\title{
PASTO NIILISTA, REPASTO HUMANISTA, CONVIVAS FANTASMAS: O JOGO COM A VIDA (E A MORTE) EM BREAKFAST OF CHAMPIONS, DE KURT VONNEGUT
}

\author{
Ravel Giordano Paz \\ Universidade Estadual de Mato Grosso do Sul \\ Em memória de Daniel Piza, \\ alma cristalina, leitor de Vonnegut.
}

\section{Resumo:}

O artigo discute a presença de elementos autobiográficos no romance Breakfast of champions, do escritor estadunidense Kurt Vonnegut, situando-os na economia da prosa experimentalcomunicativa do autor e tentando demonstrar como o que se pode denominar um jogo com a vida ajuda a dar profundidade e complexidade aos jogos narracionais e às ambiguidades ideológicas desse romance.

Abstract:

The article discusses the presence of autobiographical elements in the novel Breakfast of champions, by U.S. writer Kurt Vonnegut, placing them in the economy of experimentalcommunicative prose of the author and trying to demonstrate how a game with life aids to give depth and complexity to the novel's narrational games and ideological ambiguities.

\section{Palavras-chave:}

Kurt Vonnegut; romance estadunidense contemporâneo; ficção e autobiografia; prosa experimental; estratégias narracionais.

\section{Keywords:}

Kurt Vonnegut; contemporary U.S. novel; fiction and autobiography. experimental prose; narrational strategies. 


\section{Abertura: ao espelho com um bruxo}

A certa altura de Breakfast of champions, romance de Kurt Vonnegut publicado em 1973 e traduzido no Brasil como Café-da-manhã dos campeões, ${ }^{1}$ o narrador explica algo acerca de um livro fictício, 'escrito' por Kilgore Trout, personagem recorrente na obra de Vonnegut e frequentemente apontado como um alter ego seu: "Era uma tour de force. Era um jeu d'esprit" (VONNEGUT, 2006, p. 29). O “jogo” em questão envolveria não só a estratégia enunciativa desse romance fictício como sua mensagem, igualmente fictícia: intitulado Agora pode ser dito, o livro de Trout consistiria em uma carta na qual o "Criador do Universo" se dirige a um enunciatário não identificado para lhe declarar:

\footnotetext{
"Você está cercado por máquinas de amar, máquinas de odiar, máquinas mesquinhas, máquinas altruístas, máquinas covardes, máquinas verdadeiras, máquinas de mentir, máquinas divertidas, máquinas formais. O único objetivo delas é provocá-lo de todas os modos concebíveis, para que o Criador do Universo possa observar as suas reações. Elas são tão capazes de sentir ou racionalizar quanto relógios de pêndulos." (VONNEGUT, 2006, p. 266; aspas no original)
}

São linhas como essas que Dwayne Hoover, um vendedor de automóveis bem-sucedido mas à beira da loucura, lê e interpreta não só como verdadeiras do ponto de vista da situação enunciativa como dirigidas exclusivamente a si mesmo, passando a acreditar, portanto, que ele próprio é o único ser humano de verdade no planeta; os demais seriam robôs, máquinas insensíveis criadas exclusivamente com o objetivo de pô-lo à prova. Em sua perturbação, Dwayne não percebe que o livro de Trout é um jogo com o leitor, "qualquer um que viesse a abri-lo"; o jeu d'sprit literário, para ele, torna-se "veneno mental", fornecendo as "ideias ruins para que sua loucura pudesse ter forma e direção" (VONNEGUT, 2006, p. 29).

Tudo isso diz muito sobre a ficção de Kurt Vonnegut: o humor mórbido, as situações e maquinações extravagantes - aqui apenas beirando mas, em outros casos, mergulhando no absurdo - e, principalmente, a metalinguagem, os jogos enunciativos entre sucessivas e, em alguma medida, indissociáveis instâncias narracionais, de uma complexidade, no conjunto do romance, que é um verdadeiro desafio descrever. Esses elementos dificilmente deixarão de lembrar, ao leitor brasileiro, a obra madura de Machado de Assis, onde os jogos narracionais se aliam a uma visão de mundo em larga medida desencantada. As citações literárias inconvenientes do computador Mandarax em Galápagos (1987; no original, de 1985, Galapagos); os princípios do bokononismo em Cama-de-gato (1991; Cat's cradle, 1963); a anedota, nesse mesmo romance, acerca do que se vê entre os fios da brincadeira que o nomeia, ou seja, nada; os gestos e/ou frases-cacoetes dos narradores-personagens de Pastelão ou Solitário nunca mais (s/d [1985]; Slapstick or Lonesome no more!, 1976) e Um pássaro na gaiola (Jailbird, 1980), tudo isso condensa a espécie de desalento ou antissabedoria com que Vonnegut costuma coroar a condição humana, um pouco como o Humanitismo de Quincas Borba, as máximas de Brás Cubas ou a autocoroação de Rubião, que se cinge de nada em seu delírio napoleônico.

No caso de Vonnegut, porém, a conjunção de ceticismo, ironia e metalinguagem frequentemente desperta uma suspeita da qual o autor de Dom Casmurro tem se mostrado relativamente a salvo: a de

\footnotetext{
${ }^{1}$ Apesar de utilizarmos a tradução brasileira de Cássia Zanon nas citações (cotejando-a com o original quando necessário), referiremo-nos ao romance por seu título em inglês. Em primeiro lugar porque, como o próprio autor explica, Breakfast of champions "é uma marca da registrada da General Mills, Inc., usada num cereal para desjejum" (VONNEGUT, 2006, p. 14). Além disso, a tradução perde os sentidos implicados em break e fast, provavelmente significativos no contexto do romance: tanto pela verdadeira quebradeira do final quanto pelas várias referências à violência e à velocidade - por exemplo, dos automóveis e da pólvora, capaz de imprimir aos projéteis bélicos "velocidades incríveis" (VONNEGUT, 2006, p. 26) - na formação dos Estados Unidos.
} 
superficialidade. Talvez porque esses elementos, em Vonnegut, formem um complexo, a despeito de sua efetiva complexidade, bastante explícito, na medida em que muitas vezes o autor comenta, interroga e até relativiza o sentido, superficial ou profundo, de seus lances polêmicos. Não raro, mesmo as situações mais radicais são contrabalançados por um teor humanista e emotivo incorporado à diegese narrativa, incluindo aí - na articulação entre essas instâncias demonstrada por Gérard Gennete (s/d [1975]), aliás aqui reforçada - a voz autoral. Nos próprios atributos que o "Criador do Universo" concede às várias "máquinas" (“de amar", "de odiar", "mesquinhas", “altruístas" etc.) se nota o movimento pendular da sensibilidade e da consciência judicativa vonnegutiana. Em suma, é fácil reconhecer uma estrutura compensatória, de tipo sentimental-dickensiano, no fundo ou ao lado das tiradas críticas e irônicas, quando não niilistas, de Vonnegut. O que equivale a dizer que seu humanismo crítico beira a complacência com o estado de coisas que pretende denunciar, ainda mais num século, o XX, que guarda experiências muito mais traumáticas que o de Dickens (e Machado); e ainda mais o próprio Vonnegut tendo participado diretamente de uma dessas experiências - à qual, aliás, Walter Benjamin (1986) recusava um valor de experiência -, ou seja, a Primeira Guerra Mundial.

Essa afirmação, entretanto, corre o risco de fazer tabula rasa de algo cuja complexidade talvez seja irredutível a uma leitura passiva e apassivadora de seu objeto, ou seja, que tome os romances de Vonnegut como equações prontas, às quais cada ato de leitura cumpre apenas elucidar - e não como artefatos que se propõem a estabelecer ou ativar um jogo de certa forma indeterminado com o leitor: não, certamente, algo aleatório, mas um jogo cujo resultado não pode ser, nunca, inteiramente previsto, assim como a natureza de suas peças não pode ser inteiramente conhecida. Nada, naturalmente, que escape à condição do objeto artístico em geral: de certa forma, é sempre dos imponderáveis que a análise crítica precisa depurar as significações fortes. Em Vonnegut, porém - se estivermos certos, é claro -, os 'elementos profundos' são indissociáveis dos desafios que se lançam ao leitor.

Nesse sentido, algo da habilidade e, simultaneamente, profundidade narracional-significacional que hoje se concede amplamente ao bruxo do Cosme Velho talvez seja extensível a seu 'parente'2 do Norte, seu colega dito pós-moderno mas que ao leitor brasileiro dificilmente deixará de soar com as feições escuras, a um tempo tristes e alegres, de um Vô Negute. É, aliás, num 'canto' ao mesmo tempo dissonante e paralelo com o de um afroamericano - um 'mero' motorista de ambulância, mas “descendente direto de Francis Scott Key, o patriota americano branco que escreveu o hino nacional" e, mais ainda, de uma longa linhagem africana, da qual herdou a capacidade de "citar mais de seiscentos de seus ancestrais", sabendo "pelo menos uma história a respeito de cada um" (VONNEGUT, 2006, p. 282) -, é num triste contraponto a essa abundância de memória e sentimento, de vida, portanto, que o próprio Vonnegut, aqui nem um pouco oculto pelo Philboyd Studge que assina o prefácio de Breakfast of champions, declara: "Não tenho cultura nem harmonia humana em meu cérebro. Não posso mais viver sem uma cultura" (VONNEGUT, 2006, p. 19). Ou estamos diante de uma blague ou de uma demanda que transborda efetivamente, com tais ou quais consequências, para o vivido, e que portanto precisa ser lida e interrogada como tal.

\section{Uma tabula viva para um Breakfast amargo}

Sétimo romance de Vonnegut, Breakfast of champions é um de seus livros comercialmente mais bem-sucedidos: um dos que mais o elevaram - ou rebaixaram - à condição de autor de best-sellers. O que não deixa de conter certa ironia, na medida em que a ânsia por riqueza e sucesso pessoal é um dos alvos do romance, sobretudo na figura do protagonista (ou um deles) Dwayne Hoover, sujeito de boa

\footnotetext{
${ }^{2}$ Quando menos por certas filiações (ou, em todo caso, heranças) fundamentais, como Swift e Sterne.
} 
índole mas deformado de forma cada vez mais monstruosa, à medida em que ele sucumbe à loucura, pelo individualismo ferrenho do American way of life. ${ }^{3}$ Essa ironia se acentua pelo fato de Breakfast se situar num ponto, na trajetória literária de Vonnegut, em que certo 'estilo experimental' vonnegutiano - conquistado, basicamente, em Cama-de-gato e Matadouro 5 (2005; no original, de 1969, Slaughterhouse-five) - parece suficientemente estabelecido para que a suspeita de certa facilidade exija uma redobrada vigilância crítica.

A desconfiança de que Vonnegut manipula de forma pouco habilidosa os elementos de uma fórmula é, provavelmente, um dos fatores que determinaram uma recepção essencialmente negativa de Breakfast of champions como a Peter Messent, o qual, na conclusão de sua análise do livro, considera que nele Vonnegut se depara com uma espécie de "cul-de-sac": "His stylistic approach basically fails and comes close at times to mere childishness" (MESSENT, 1974, p. 113-114). Mas, predisposições à parte, que grau de verdade pode conter esse julgamento? Afinal, se interpretar os jogos vonnegutianos em termos de "abordagem estilística" constitui uma redução evidente, é possível, de fato, apontar elementos em Breakfast of champions que parecem confinar com uma visão pueril dos conflitos tematizados.

Basta notar, por exemplo, que o sempre adiado relato das atrocidades praticadas por Dwayne Hoover, quando consumado, parece desvelar atos não tão atrozes assim. Dwayne fere várias pessoas, e pelo menos duas deles gravemente - seu próprio filho e a secretária e amante -, mas o fato de que nenhuma morte chega a ocorrer pode soar como uma decepção, em se tratando do clímax de um livro que, desde o início, situa seus personagens e sua ambientação no âmbito de um processo histórico cruel; um processo de formação territorial no qual "piratas do mar" desempenharam um papel fundamental: homens que, afirmando ter criado "um governo que se tornou um farol de liberdade a seres humanos de todos os lugares", na verdade "usavam seres humanos como maquinaria, e mesmo depois que a escravatura foi abolida, por ser tão constrangedora, seus descendentes seguiram vendo os seres humanos comuns como máquinas" (VONNEGUT, 2006, p. 24-25). Após investir contra datas e símbolos nacionais, Vonnegut conclui da seguinte forma sua pequena preleção histórico-moral:

Eis como os piratas conseguiram tomar tudo o que quiseram de todas as pessoas: eles tinham os melhores barcos do mundo, eram mais malvados do que qualquer um e tinha a pólvora, que era uma mistura de nitrato de potássio, carvão e enxofre. (...) A principal arma dos piratas do mar, no entanto, era a capacidade de surpreender. Ninguém era capaz de acreditar, até que fosse tarde demais, o quanto eles eram cruéis e gananciosos. (VONNEGUT, 2006, p. 25-26)

A rigor, os atos de Dwayne - que, como já vimos, tomará as pessoas literalmente por máquinas -, mesmo (ou até porque) insanos, parecem não fazer jus a essa condição de crueldade e ganância extremas, como tampouco o faz a ideia de que a abolição da escravatura ocorreu "por ser tão constrangedora", e não por motivos econômicos.

Mas é difícil supor que Vonnegut não se dê conta de tudo isso. No segundo caso, chega a ser estranho, para o leitor familiarizado com a maquinaria digressiva vonnegutiana, que o comentário não se desdobre em outro, mais ácido, mencionando, por exemplo, a Guerra da Secessão. Pode-se supor, portanto, que o romancista deixa esse procedimento a cargo do leitor, assim como a relativa frustração do jogo de expectativas em torno do clímax parece relacionada com um procedimento desdramatizante,

\footnotetext{
${ }^{3}$ A rigor, o conteúdo do livro de Trout - ou melhor, da 'mensagem' que o "Criador do Universo" registra nele - que catalisa o surto psicótico de Dwayne, é uma ampliação da visão dos "seres humanos como maquinário" que Vonnegut atribui aos "piratas do mar" e, por meio deles, ao individualismo norte-americano. A nosso ver, o behaviorismo ou determinismo biológico de Vonnegut (atuante sobretudo em Galápagos) é uma blague, ou melhor, um dos desafios que seu leitor deve superar.
} 
coerente com uma prosa mais zelosa da reflexão que da catarse; esta, justamente uma expectativa em jogo, não uma finalidade. Embora seja difícil determinar o peso exato disso tudo no romance, o fato é que a superficialidade, em Vonnegut, é muitas vezes, e claramente, um efeito buscado, seja como um acalanto puerilizante ou como uma atitude provocadora diante do leitor. Seja como for, a partir do momento em que é incorporada a um tipo de jogo ao qual o leitor é chamado a participar ativamente, a própria puerilidade se torna irredutível à mera puerilidade.

E não se pode atribuir nenhum sentido digno à palavra “jogo", em Vonnegut, se ela não se reportar - em respeito, mesmo, aos convidados (incluindo aí a figura fantasmal-demandante do leitor) com que se joga - a algo mais sério que uma função meramente lúdica. E é justamente nesse aprofundamento que o vivido constitui um dado essencial, em certos aspectos com uma radicalidade inédita - ao menos na obra de Vonnegut-, em Breakfast of champions. Nem Cama-de-gato nem Matadouro 5 contêm, por exemplo, uma passagem similar a esta:

- Este livro que você está escrevendo é muito ruim - eu disse a mim mesmo por trás dos meus escapes ${ }^{4}$.

- Eu sei - respondi.

- Você tem medo de se matar como a sua mãe se matou - eu disse.

- Eu sei - respondi.

-..

Lá no bar, espiando através dos meus escapes para um mundo que eu mesmo havia inventado, falei baixinho a seguinte palavra: esquizofrenia. (...)

Não sabia e não sei com certeza se eu tenho a doença. Mas sabia e sei o seguinte: estava ficando monstruosamente desconfortável por não conseguir concentrar a minha atenção a detalhes da vida que eram imediatamente importantes e por me recusar a acreditar no que meus vizinhos acreditavam. (VONNEGUT, 2006, p. 205-206; grifos do autor)

Na continuidade dessa sequência 'confessional' algo abrupta e espantosa, Vonnegut - ou como quer que nomeemos a figura autoral que aí fala - assegura: "Estou melhor agora". E mais uma vez, como que para se certificar disso: "Palavra de honra: estou melhor agora" (VONNEGUT, 2006, p. 206). Breakfast of champions não é, certamente, o primeiro livro onde se cogita, explicita e, mais ainda, dramatiza a possibilidade de um quadro psicopatológico na raiz das demandas autorais determinantes de sua forma e conteúdo: Lautréamont, Baudelaire, Strindberg, Artaud e muitos outros praticaram gestos semelhantes, e não raro com maior radicalidade. Isso, entretanto, não impede que se inquira pelos sentidos, ou melhor, as possibilidades de sentido catalisadas por esse gesto na economia desse livro onde ele se articula a jogos enunciativo-narracionais extremamente conscientes.

Do ponto de vista de uma análise ideológica, os elementos de metalinguagem e autorreferencialidade, em Vonnegut - incluindo aí a profusão às vezes delirante dos jogos enunciativos, a autoironia quase perene, os bordões irônico-fatalistas, como "Coisas da vida", "E assim por diante" etc. -, podem ser vistos como parte de uma lógica niveladora, senão dissolutiva, dos conflitos. Entretanto, como a passagem que transcrevemos sugere, os jogos metalinguísticos são também um meio pelo qual a prosa vonnegutiana se radicaliza e autoproblematiza num sentido irredutivelmente - para além ou aquém de toda literariedade - biográfico. São, realmente, fatos biográficos os mencionados na passagem referida e muitas outras, que alçam os jogos enunciativos de Breakfast of champions ao que se pode chamar um jogo com a vida; ou melhor, com a vida e a morte: não apenas no sentido da alusão - em algum sentido, como vimos,

${ }^{4}$ Os "escapes" (leaks), no caso, são os óculos escuros com vidro espelhado usados pelo autor-personagem. Trout - e, com ele, Vonnegut - chama assim todas as superfícies espelhadas, cuja função seria justamente a de proporcionar fugas da realidade. 
extraliterária - a um disseminado risco de vida ${ }^{5}$, mas também no sentido dos fantasmas, pulsionais ou 'reais' (Galápagos, por exemplo, é narrado pelo fantasma do filho de Kilgore Trout), que habitam a prosa de Vonnegut. Nesse sentido, os romances-tabuleiros vonnegutianos assemelham-se a mesas de espíritos, nas quais se invocam fantasmas vivos para jogar entre si e conosco, com nossas ânsias de violência, catarse, medo, proteção, alívio, perdão, etc.

Ao contrário de Matadouro 5, cujo episódio central é diretamente decalcado de uma experiência histórica e pessoal de Vonnegut na Primeira Guerra, o enredo central de Breakfast of champions - ou melhor, a intersecção de seus dois enredos centrais no encontro de Trout e Dwayne, com as consequências disso - não é de fundo autobiográfico. Aqui o vivido se insinua de forma ao mesmo tempo mais tangencial e mais ostensiva, disseminando-se em vários níveis e nichos da narração, da discursividade autoral à composição de situações e personagens. Outro caso, além do discurso sobre a esquizofrenia em tom de desabafo irônico, é a comparação entre a esposa de Dwayne Hoover e a do escritor (ou seja, a figura autoral Vonnegut). Aqui o tom é mais sério, embora de uma seriedade que reivindica certa simplicidade sentimental como um valor, numa das manifestações repentinas do humanismo vonnegutiano. Depois de declarar, com seu usual humor negro, que ambas eram "loucas varridas", o autor-narrador (aqui, ainda não personagem, tal como surgirá nos últimos capítulos) solicita a atenção do leitor:

Escute: a mãe de Bunny [o filho de Dwayne] e a minha mãe eram seres humanos diferentes, mas ambas eram lindas de um jeito exótico e ambas se exaltavam com conversas caóticas sobre amor, paz, guerras, maldade e desespero, de dias melhores que estavam por vir, de dias piores que estavam por vir. E ambas as nossas mães se suicidaram. A mãe de Bunny comeu Drâno. Minha mãe tomou pílulas para dormir, o que não era nem de perto tão horrível. (VONNEGUT, 2006, p. 192)

Mais do que um procedimento atenuante, essa última frase tem o efeito de revelar o mecanismo em ação aí: é, de fato, enquanto relação conscientemente trabalhada, e cuja autoconsciência deve se comunicar à consciência do leitor, que a aproximação entre a personagem e a pessoa instauram um jogo. $\mathrm{O}$ escritor (ou sua primeira e transparente 'máscara', Philboyd Studge), vale notar, alude à loucura da mãe desde o prefácio do livro, quando comenta que ela "destruiu o cérebro com produtos químicos que deveriam fazêla dormir” (VONNEGUT, 2006, p. 17). Em outro caso, é a relação Dwayne/Vonnegut, também delineada desde o Prefácio, que se reforça por via de uma outra ocorrência biográfico-afetiva, mais simples e, por isso mesmo, mais positiva, mas que só se reconhece a partir de outro texto: o Prólogo de Pastelão ou solitário nunca mais, onde sabemos que, assim como Dwayne com seu cão Sparky (VONNEGUT, 2006, p. 31), o escritor se comprazia em ficar "rolando nos tapetes" com seus cachorros (VONNEGUT, s/d [1985], p. 10).

Assim, Kilgore Trout, tão evidentemente (mas não completamente) simétrico, em sua condição de personagem-escritor de ficção científica, à persona real ou figural de Vonnegut, e que até no nome traz um rastro identitário autoral, não é o único personagem com a marca de um alter ego vonnegutiano em Breakfast of champions. O que não reduz sua importância na economia da narrativa e mesmo no âmbito das relações autobiográficas, sem dúvida mais incisivas em sua figura; mas serve, pelo contrário, para sublinhar que essas relações não podem ser reduzidas à visão do personagem como alter ego autoral.

\footnotetext{
${ }^{5}$ Vários romances de Vonnegut - Galápagos, Pastelão e Cama-de-gato, por exemplo -, culminam ou se desenvolvem em situações apocalípticas ou pós-apocalípticas. No próprio Breakfast of champions, o tempo da narração (ficcional, é claro) se situa num futuro em que os seres humanos são "os únicos animais restantes na Terra" (VONNEGUT, 2006, p. 36). Essa, digamos possibilidade terminal e as grandes catástrofes do século XX - a Primeira e a Segunda Guerra Mundial - constituem espécies de horizontes ou reguladores éticos da ficção de Vonnegut.
} 
Espelho invertido, "escape" quebrado, pai do filho do pai de si mesmo, e assim por diante, Trout suscita questões de paternidade e autoria machadiano-joyceanas. Mas diante do aparente descalabro com que isso se configura nele, uma outra questão avulta: a de por quê tudo isso.

\section{Kilgore Trout: um 'alteroutros' e um jogo tortuoso}

Que Trout se liga não apenas à figura de Kurt Vonnegut, Jr. (como nosso autor assinou suas primeiras obras), mas também à do pai deste, é outro elemento explícito em Breakfast of champions. Como uma criatura frankensteiniana mais aparentada a seu criador que a de Mary Shelley, o escritor de ficção fictício é descrito como portando as pernas, as varizes e, finalmente, a voz de Vonnegut pai, ${ }^{6}$ em passagens nas quais o filho, Vonnegut-autor-narrador, raramente deixa de revelar certa crueldade. Depois de nos declarar ter sido ele, autor-narrador, quem inventou Kilgore Trout (como declarará, depois, ao próprio Trout), e de descrever os dentes acavalados e os cabelos brancos, compridos e emaranhados com que o dotara, Vonnegut arremata essa primeira descrição, aliás, composição física do personagem: "Dei-lhe as mesmas canelas [legs] que o Criador do Universo deu ao meu pai quando meu pai era um velho digno de pena. Eram cambitos de um branco pálido. Não tinham pelos. Eram fantasticamente incrustadas com veias varicosas" (VONNEGUT, 2006, p. 46). Na menção seguinte às pernas (de novo legs, que Zanon reduz a "canelas"7) varicosas de Trout, a imagem é ainda mais irônica: "Ele levantou as pernas das calças de modo que suas canelas grotescamente ornamentadas ficassem expostas" (VONNEGUT, 2006, p. 49).

Há um episódio específico, no entanto, em que a insistência nesse fato, aliás, nesse ato atributivo - o de que emprestar ao personagem escritor os membros inferiores (as pernas e, com elas, as canelas e os pés) do pai do narrador ou escritor-autor quando "velho, muito velho" (VONNEGUT, 2006, p. 234) -, tornase recorrente. Numa dessas recorrências, o comentário parece se investir de certo teor afetivo: "Kilgore Trout tinha as canelas do meu pai. Elas eram um presente para mim. Eu também lhe dei os pés do meu pai, que eram longos, estreitos e sensíveis. Eram azuis-celestes. Eram pés artísticos" (VONNEGUT, 2006, p. 234). Vonnegut (ou "Philboyd Studge") já havia declarado, no Prólogo, que Breakfast of champions "é o livro que dou a mim mesmo pelos meus cinquenta anos" (VONNEGUT, 2006, p. 17). Na sequência da narrativa, porém, sabemos o que acontece com Trout e seus "pés artísticos" - como voltamos a ler -, que ele havia exposto ao enrolar as calças e tirar os sapatos e as meias para atravessar um canal criminosamente contaminado por produtos químicos:

Eles foram cobertos de uma vez só por uma substância plástica clara que havia na superfície do riacho. Quando, com alguma surpresa, Trout levantou um dos pés de dentro d'água, a substância secou instantaneamente, forrou seu pé numa substância fina e justa semelhante a madrepérola. Repetiu o processo com o outro pé. (VONNEGUT, 2006, p. 234)

Esse duplo passo, metade acidental e metade atoleimado, não terá qualquer consequência na suposta linha-mestra da narrativa, ou seja, a que leva ao clímax constituído pelo surto psicótico de Dwayne Hoover, mas para o próprio Trout será o início de um pequeno rito de tortura; um rito, aliás, cujo desfecho -

\footnotetext{
${ }^{6}$ E também o smoking ("tuxedo") - ou pelo menos sua imagem e semelhança - com que Trout viaja a Midland, e que era "muito parecido com um smoking que eu tinha visto meu pai vestir quando ele já era um homem muito, muito velho" (VONNEGUT, 2006, p. 48).

${ }^{7}$ A distinção entre "pernas" e "canelas", nem sempre levada em conta pela tradutora, é a nosso ver importante, no sentido de que as pernas constituem, digamos, uma parcela mais significativa de Vonnegut pai em Kilgore Trout. No contexto dos acontecimentos sinistros que mencionaremos a seguir isso não é indiferente.
} 
digamos, 'refrescante' - também encerra o enredo 'propriamente dito' (seguindo-se, porém, um epílogo), com o personagem, que também fora atacado por Dwayne, arrancando "faixas e pedaços de plástico de suas canelas e pés que queimavam de calor ["his burning shins and feet"] na ambulância" (VONNEGUT, 2006, p. 292). Esse fecho meio tangencial não é inteiramente despropositado; afinal, trata-se também, aquele duplo passo, de um movimento fundamental rumo ao clímax dramático: o canal poluído separava Trout justamente do hotel onde ocorrerá o encontro com Dwayne. Entretanto, sua dissociação dos atos de Dwayne é um índice de que Trout é investido, aí, de uma determinada função - obviamente sacrificial - no interior de uma economia, digamos, 'especificamente' biográfico-autoral. E menos sacrificial do que imolatória, no sentido de ações-enunciações mais zelosas da crueldade que do sacrifício enquanto prática ligada ao sagrado (o que não significa, como veremos, que a noção de sagrado não esteja em jogo aí), em consonância com a sugestão de um bode expiatório insignificante e miserável, uma espécie de vítima utilitária ou pau-pra-toda-obra, de que a própria condição rebaixada - a começar pelo sobrenome, evocando origens operárias ${ }^{8}$ - de Trout parece investi-lo. Tanto mais que esse rebaixamento incisivo (veremos, ainda, até que ponto) não obsta e até reforça, inclusive pelo contraponto com o rico e 'integrado' Dwayne, sua não menos cabal centralidade, embora não exclusiva, no romance.

O que, naturalmente, torna o personagem o receptáculo ideal dos fantasmas autorais, para além, inclusive, do enredo 'propriamente dito'. Assim, na cena que fecha a narrativa9', não apenas Trout é investido da voz e, por essa via, da presença do pai de Vonnegut, como outro fantasma, o materno, permite-se ver por meio dele: "Sua voz era a voz do meu pai. Eu ouvia o meu pai - e via a minha mãe no vácuo. Minha mãe ficou muito, muito longe, porque havia me deixado um legado de suicídio ${ }^{10}$ " (VONNEGUT, 2006, p. 307; grifo do autor). As palavras que esse Trout-fantasma paterno grita nesse momento em que o autornarrador - agora, declarada e personificadamente o Criador e doador dos destinos do pequeno ou grande mundo que vimos em movimento - decide se desfazer dele é outro exemplo do sentimentalismo crítico e pendular de Vonnegut (2006, p. 307; grifos do autor): "Faça-me jovem, faça-me jovem, faça-me jovem!". Como em "Viver!", conto de Machado em que Ahasverus, o judeu errante, sonha com a vida ainda prestes a sucumbir no fim dos tempos, Vonnegut afirma aí a legitimidade, para além do 'merecimento' que uma consciência judicativa se permita lhe atribuir ou não, de toda e qualquer demanda de vida.

O sadismo evidente, porém, não é mero detalhe. Pode-se supor que ele se deixa subsumir num sentimento mais amplo, mas isso não elimina a pergunta por seu sentido. Ainda no prefácio, StudgeVonnegut aventava que, com esse livro, ele estaria tentando "limpar a minha mente de todo o lixo que há lá dentro - os cus, as bandeiras, as calcinhas", e também "jogando fora personagens de meus outros livros. Não farei mais espetáculos de marionetes”. Entremeado pelo já citado comentário acerca da ausência

\footnotetext{
${ }^{8}$ Mais exatamente, pesqueiras, o que também se liga, evidentemente, a um fundo ou contraponto sublimizante no personagem, de um sublime irônico ou diminuído - até em sua, digamos, fluvialidade, e não oceanidade: truta é um peixe de água doce -, mas nisso mesmo ligado ao topos vonnegutiano do sublime enquanto simplicidade ou puerilidade. Sem deixar, ao mesmo tempo, de lembrar os ecos de Homero, Stevenson, Swift, Melville - mas, sobretudo, Mark Twain, narrador-cantor do Mississipi - na prosa de Vonnegut, e que não estão em desacordo com a imaginação viajante - embora cósmica - de Trout, na qual a proliferação de mundos e galáxias guarda como que uma nostalgia das histórias de marinheiro. Não por acaso, Vonnegut escreveu Galápagos, ficção (anti)científica oceânica onde a certa altura o fantasma do nosso mesmo Trout - que, assim como os pais de Vonnegut, não desapareceu dos romances deste - pergunta ao fantasma de seu filho, Leon Trotski Trout (mencionado em Breakfast como o jovem "Leo", menos revolucionário que revoltado com o pai), se ele "já se cansou de navegar na nau dos insensatos" (VONNEGUT, 1987, p. 227). Trout, cumpre ainda notar - retomando nossa questão de classe (a qual, como afinal o 'trotskismo' do personagem não deixa de sugerir, tem no mínimo alguma importância em Vonnegut) -, é operário de profissão. E nisso tudo cumpre remeter ao já citado ensaio de Benjamin (1986).

${ }^{9}$ Ainda se segue um grande "ETC." e um perfil de Vonnegut chorando, ambos desenhados pelo escritor.

${ }^{10}$ Embora posterior a essas palavras, a tentativa de suicídio efetivamente realizada pelo escritor, em 1984, certamente ajuda a mensurar seu alcance.
} 
de "cultura e harmonia humana", esse fio discursivo prossegue na afirmação de que "este livro é uma calçada entulhada de tralhas, lixo que jogo por cima dos ombros, enquanto viajo no tempo de volta ao dia onze de novembro de mil novecentos e vinte e dois", ou seja, o dia do nascimento de Kurt Vonnegut, Jr. A mesmo data em que, décadas depois, ao fim da Primeira Guerra Mundial, seria celebrado o Dia do Armistício, um dia em que "Deus falou claramente à humanidade" (VONNEGUT, 2006, p. 18-19). Entretanto, prossegue o narrador:

O Dia do Armistício se tornou o Dia dos Veteranos. O Dia do Armistício era sagrado. O Dia dos Veteranos não é.

Por isso vou jogar o Dia dos Veteranos por cima dos ombros. Mas vou manter o Dia do Armistício. Não quero jogar fora nada sagrado.

O que mais é sagrado? Ah, Romeu e Julieta, por exemplo.

E toda música também é. (VONNEGUT, 2006, p. 19-20)

Não seria o caso, infere-se, de Kilgore Trout. Mas e do que se agrega a ele? Devolver os pais ao abismo como encenação de um renascimento passa, aqui, por uma intencionalidade sacrílega ou dessacralizadora em relação a essas figuras biográficas? A julgar por um outro rito a que é submetida uma dessas figuras - naturalmente, a que mais diretamente se agrega a Trout -, a resposta, pelo menos nesse caso, parece inevitavelmente positiva. $\mathrm{O}$ que não encerra a questão mas constitui um dado fundamental dela. Vejamos, então, que outro rito é esse; mas nesse ponto é importante lançarmos uma visão panorâmica a Breakfast of champions.

No romance, a trajetória de Trout é narrada paralela e alternadamente com a de Dwayne Hoover: este rumo à loucura e aquele rumo a um festival de artes em Midland, onde eles afinal terão seu funesto encontro no restaurante de um dos hotéis de Dwayne. Escritor prolixo mas desconhecido, Trout é autor de ficções grotescas mas, de fato, algo impressionantes em suas sugestões metafóricas, e que são impressas apenas em revistas pornográficas, invariavelmente ilustradas com imagens de sexo sem relação alguma com seu conteúdo. Convidado, para seu pasmo e por obra de um admirador milionário, para realizar uma conferência num festival de artes, Trout inicia uma pequena peregrinação, cuja etapa mais importante pelo menos antes do encontro com Dwayne - é uma breve mas penosa passagem por Nova York, ainda no início da narrativa: ao sair de um cinema pornô onde passara parte da noite, o personagem é atacado, raptado e, ao que tudo indica, violentado sexualmente por uma gangue de marginais. O último detalhe não é explícito, sem, no entanto, que se dê outra explicação para a situação de Trout quando desperta após o rapto: "Quando deu por si, estava de quatro numa quadra de handebol (...). Estava com as calças e as cuecas pelas canelas. Tinham levado todo o seu dinheiro. (...) Pingava sangue de um ouvido" (VONNEGUT, 2006, p. 88).

Esse episódio, ao qual o próprio Trout não dá muita atenção, ou melhor, que ele parece desprezar em consonância com uma 'filosofia' fatalista e conformista, meio leibniziana - todos os eventos do universo seriam absolutamente necessários -, não tem desdobramentos na sucessão dos eventos principais; mas isso mesmo, de certa forma, além da própria sutileza da situação (não, propriamente, ambiguidade, pois não há outra sugestão), a investe de uma singularidade nada desprezível: trata-se do único fato em $s i$ mesmo importante, no bojo da narrativa, que o narrador se abstém absolutamente de comentar, explicar, comparar, relativizar etc. O que não impede que esse episódio se ligue a toda uma rede associativa de imagens e comentários que pontuam a narrativa, e que talvez possa ser lida como uma rede metonímica que encontraria justamente nele seu sentido, senão último, pelo menos mais forte.

Também o início dessa rede remete ao Prefácio, onde Vonnegut explica sua dedicatória a Phoeby 
Hurty, apresentada como uma mulher inteligente e admiráve ${ }^{11}$, de cujos filhos ele havia se tornado amigo e que o havia contratado, ainda adolescente, como redator publicitário; mais ainda: que havia ensinado, ao jovem Vonnegut e aos próprios filhos, a serem "inconvenientes não apenas em conversas sobre questões sexuais como também a respeito de história norte-americana e heróis famosos, sobre a distribuição da riqueza, sobre a escola, sobre tudo" (VONNEGUT, 2006, p. 15). Como um exercício desse aprendizado - necessariamente, porém, sem a delicadeza das inconveniências de Phoeby -, pouco adiante Vonnegut inscreve um, digamos, ponto de partida mais 'concreto' (no sentido em que os concretistas chamam sua poesia de "concreta") para esse fio metonímico; trata-se, na verdade, do primeiro desenho de Vonnegut no prefácio, a nosso ver indissociável do corpo narrativo, e que surge no momento em que o escritor explica que está "programado" para atos como insultar o hino e a bandeira estadunidenses e "rabiscar desenhos de uma bandeira nazista, um cu e um monte de outras coisas", apresentando, como exemplo da "maturidade" de suas ilustrações para o livro, o "desenho de um cu":

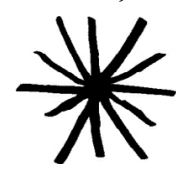

(VONNEGUT, 2006, p. 18)

A 'citação' gráfica não serve apenas para resguardar os direitos do humor, aqui algo sórdido, de Vonnegut; ela também visa dar ao leitor a chance de se perguntar, conosco, se a espécie de cintilação desse desenho não sugere, para além de uma ofensa gratuita, um ato de alguma forma iluminador, no sentido mesmo de uma metáfora-chave de Breakfast of champions (não passando ao largo, por exemplo, do sentido 'alimentício' desse título). Seja como for, a imagem, pictórica ou verbal, do asshole 12 (não anus, "ânus") é retomada em vários pontos do romance, geralmente em contextos tão pejorativos quanto sinistros. Quando, por exemplo, um desenho igual ao que vimos aparece no corpo da narração, ele é antecedido de outro, de uma seringa pontiaguda e gotejante, e de uma frase sobre pessoas que às vezes "enfiavam elementos químicos ruins em seus cus" (VONNEGUT, 2006, p. 83). Pouco adiante, é um remédio "para ser passado no cu" o que ingerem, agora pela boca, "duas jovens prostitutas" (VONNEGUT, 2006, p. 84). Trata-se, aliás, da passagem de Trout por Nova York, cujo episódio culminante ${ }^{13}$ já conhecemos.

E assim por diante: da proteção de privada no hotel de Dwayne que impediria que "animaizinhos

\footnotetext{
${ }^{11}$ Os prefácios e narrativas de Vonnegut quase sempre contêm uma dessas figuras femininas, ao mesmo tempo fortes, equilibradas e maternais, e das quais a mais utópica (ou distópica, dependendo do ponto de vista) é, provavelmente, a Mary Hepburn de Galápagos, que, juntamente com o sórdido James Wait, dá origem à pós-humanidade biologicamente regressiva (mas feliz) do romance. Em Matadouro 5, outra Mary - O'Hare - teria inspirado ao autor o subtítulo do romance (“A cruzada das crianças") com um comentário: "Vocês eram crianças durante a guerra..." (VONNEGUT, 2005, p. 21; grifo do autor).

${ }^{12}$ Também é curioso notar, no que se refere à "cintilação" do desenho que acabamos de reproduzir, sua semelhança com as "estrelinhas" que aparecem em outras páginas do livro. E levando um pouco mais longe essas analogias antissublimes, podemos perguntar, ainda, se não há a sugestão de um trocadilho - ou seja, um trânsito - entre asshole e o holy repetidamente invocado nesse mesmo Prefácio.

${ }^{13}$ De certa forma, não só para Trout, pois sua suspeita de que seus agressores podiam ser, na verdade, "um gás inteligente de Platão" (VONNEGUT, 2006, p. 88) gera pânico na cidade. Se essa suspeita é sincera ou falsa, ou seja, fruto de uma crença (delirante ou fundamentada) ou um jeu d'esprit,é outro problema. O fato é que, constitua um complexo coerente ou não, Trout conjuga um pouco - mais a nível, digamos, ideológico - do que Vonnegut vê de pior no mundo e, quiçá, em si mesmo; por exemplo, a inteligência crítica que transparece nas primeiras páginas, e que depois parece se tornar ou, de alguma forma, conviver com o já referido conformismo 'leibniziano', tornando-se afinal, nas prolepses do futuro apocalíptico, militância pacifista e humanista ativa, cuja síntese positiva Vonnegut inscreve no epitáfio-citação de seu personagem: "Kilgore Trout - 1907-1981 - 'Somos saudáveis apenas na medida em que nossas ideias são humanas"” (VONNEGUT, 2006, p. 30).
} 
em forma de saca-rolha rastejassem para dentro do seu cu e comessem sua fiação" (VONNEGUT, 2006, p. 92) à ofensa com que o filho de Trout se despede do pai ao entrar para os Fuzileiros Navais - "Você se enfiou no próprio rabo [de novo asshole, aqui em tradução atenuada] e morreu" (VONNEGUT, 2006, p. 123), e ainda à caracterização, por três personagens diferentes, ${ }^{14}$ da cidade de Midland como "o cu do Universo" -, asshole parece, de fato, uma palavra-chave em Breakfast of champions. Sem, entretanto, que em nenhum momento se explicite isso que surge como uma sugestão, não obstante, em si mesmo explícita o suficiente para tornar toda essa proliferação verbal (em torno de algo, note-se bem, interdito) extremamente constrangedora, senão vexaminosa. Para nós, leitores, e, é claro, os, digamos assim, núcleos semânticos envolvidos: pois quem lê Kilgore Trout "de quatro numa quadra de handebol”, "com as calças e as cuecas pelas canelas" (VONNEGUT, 2006, p. 88), dificilmente não 'vê', aí, as pernas do pai de seu criador.

Além disso, essa rede de sugestões ou referências anais convive com outras, semanticamente relacionadas: aos órgãos sexuais, nas menções aos "castores" (gíria dos paparazzi para vaginas) e a medidas de pênis (que, a partir de certo momento, e de forma aparentemente gratuita, tornam-se realmente proliferantes, chegando a dificultar sua contagem), e a situações propriamente sexuais, quase sempre em contextos igualmente grosseiros ou grotescos, envolvendo, por exemplo, um estuprador (de pelo menos duas mulheres, com consequências funestas para ambas, além de um aborto) ou a nomeação pejorativa do ato sexual como "foder" (fucking), e disto como "a forma de fazer bebês", sendo que "chegavam cada vez mais bebês - chutando e berrando, gritando por leite" nesse "planeta devastado", pois, embora a maioria das pessoas vivesse em países miseráveis, e em alguns lugares chegavam a tentar "comer lama ou chupar pedras enquanto bebês nasciam a poucos metros de distância", elas "continuavam fodendo o tempo todo" (VONNEGUT, 2006, p. 26-27). E há ainda a questão da sexualidade e do destino do filho de Dwayne: homossexual assumido, Bunny é não só rejeitado pelo pai (que, no entanto, o emprega como pianista no hotel onde ocorre o clímax) como um dos mais gravemente feridos por ele.

Ainda que se possa articular alguns desses dados à cena sinistra de Nova York, é evidente que eles a ultrapassam, inclusive em direção a outros topoi autobiográficos: o materno, por exemplo. Mas nada disso elimina a interrogação que já fizemos: por que um rito tão cruel envolvendo a figura do pai? Por que ativar a imaginação do leitor com situações não declaradas mas evidentes e, ainda, fazê-lo supor outras? Que dizer, por exemplo, desse episódio mais próximo do final do livro, quando, vendo Vonnegut (autornarrador-personagem) prestes a ser atacado por um cão feroz, Trout desanda a fugir covardemente? Com as pernas de Vonnegut pai, é claro... Tudo o que a suspeita de superinterpretação obriga a crítica silenciar, o 'leitor comum' - porém atento - dificilmente deixa de cogitar.

Não é difícil cavar ou desencavar explicações psicanalíticas, menos ou mais complexas, para essa ritualística, digamos, 'edipiana', e que poderiam ser confirmadas com elementos colhidos nessa e em outras obras de Vonnegut. Por exemplo, na afirmação de Leon Trotski Trout, o narrador-fantasma de Galápagos, de que Kilgore fora “um péssimo pai” (VONNEGUT, 1987, p. 228), ou numa associação, que entretanto só poderia ser muito relativa, da figura paterna real com a de Felix Hoenniker, pai do narrador de Cama-de-gato e, nessa ficção apocalíptica, um dos responsáveis pela construção da bomba atômica.

\footnotetext{
${ }^{14}$ Sendo o último deles, e fazendo-o em tom imperativo - "Isso aqui tem que ser o cu do Universo" (VONNEGUT, 2006, p. 207; grifo do autor) -, o pintor minimalista Rabo Karabekian; um nome que, nesse contexto, torna inevitável cogitar se Vonnegut não conhecia um pouco de português. Mas é também esse personagem quem declara a convicção vonnegutiana que o Philboyd-Vonnegut do prefácio não ousara declarar: que também a vida humana é sagrada, ou melhor, que a consciência é "tudo o que está vivo e talvez seja sagrado em cada um de nós" (VONNEGUT, 2006, p. 232). Com seu dom de captar e fixar a alma dos seres com meras faixas de tinta sobre a tela, Rabo - renomeado Sarkis Karabekian no posterior Barba-Azul (s/d [1988]; no original, de 1987, Bluebeard) - é, no fim das contas, uma das ambíguas expressõessínteses do humanismo, idealismo e, quiçá, espiritualismo vonnegutianos.
} 
Mas tampouco faltam, nos prefácios e nos comentários dos narradores de Vonnegut, menções afetuosas e até elogiosas ao pai do escritor, assim como as situações ficcionais referidas contêm muitos atenuantes: depois daquela censura, por exemplo, Leo Trout emenda que seu pai, Kilgore, "sempre cumprira suas promessas e nunca mentira para mim" (VONNEGUT, 1987, p. 228). E, longe de ter sido um cientista ou um escritor mais ou menos louco, Kurt Vonnegut pai foi um arquiteto e pintor, do qual o filho diz, por exemplo - e com orgulho talvez ambíguo mas ainda assim indisfarçado -, que projetou o edifício onde "ainda funciona com sucesso" a loja de departamentos para a qual a admirável Phoeby Hurty escrevia seus anúncios (VONNEGUT, 2006, p. 14).

Diante disso, ou seja, de algo que, lido rigorosamente como um ato sacrificial-judicativo, confina com uma maior ou menor injustiça, cabe perguntar se não seria muito mais a Vonnegut Jr., e não a seu pai ou a seus leitores, que vexaria tudo isso. Mas também se não seria justamente disso, ou melhor, de $u m$ pouco mais que isso que se trata aqui: de um gesto pelo qual o jogo com a vida constrange, discreta mas profundamente, o sempre alegado 'fechamento da arte'. A última medida peniana que o narrador-figura autoral - resgatemos, por precaução, essa nomeação discreta - fornece no livro é nada menos que a sua própria, seguida de um comentário que parece vir a guisa de "sic", ou seja, de uma confirmação de que não estamos diante de um erro de revisão: "Meu pênis tinha sete centímetros e meio de comprimento e doze centímetros e meio de diâmetro. ${ }^{15} \mathrm{O}$ diâmetro era um recorde mundial, até onde eu sabia" (VONNEGUT, 2006, p. 296). Essa ‘confissão’ não menos abrupta que aquela sobre a esquizofrenia paira inexplicável por um tempo, até que, páginas adiante, nos deparamos com uma justificativa parcial - não mais que isso - para ela: pois o episódio de cujo preâmbulo ela participa é aquele no qual, esperando por Kilgore Trout numa rua escura de Midland, o narrador-autor é atacado por um cão ferocíssimo; uma ameaça que, embora não chegando a atingi-lo, produz em seu corpo reações químicas "sem precedentes na história da medicina":

Pode ter acontecido porque alguma fiação tenha entrado em curto-circuito ou alguma vedação tenha estourado. De qualquer modo, eu também retraí meus testículos para dentro da minha cavidade abdominal, puxando-os para dentro da minha fuselagem como o trem de pouso de um avião. Agora, dizem que apenas uma cirurgia pode tirálos para fora novamente. (VONNEGUT, 2006, p. 301)

O que essas situações tecnicamente ficcionais - mas também descrições pessoais, ainda que remetendo ao lusco-fusco de uma pessoa-personagem - guardam de biograficamente factual? Teria esse pequeno acúmulo de grotescos alguma relação com a situação não menos grotesca protagonizada por Trout em Nova York? É no episódio do ataque do cão, vale notar, que Trout foge em disparada, com uma covardia da qual não deu mostras nas calçadas da perigosa $42^{\text {nd }}$ Street. Ainda que excessivas, essas cogitações não são imotivadas, no âmbito de uma economia narracional onde autor, personagens, criação ficcional e memórias pessoais se imiscuem de formas tão complexas. Mas o desafio que Vonnegut lança ao leitor não é o de responder a essas questões irrespondíveis, e sim o de buscar, talvez menos no livro do que em si mesmo, a coisa certa - ou melhor, a menos equívoca possível - a fazer diante delas. Ou melhor: das demandas vivas que elas nos comunicam.

\footnotetext{
${ }^{15}$ No original, que segue o padrão de medida estadunidense, "three inches long and five inches in diameter" (VONNEGUT, 2000, p. 219), ou seja, três polegadas de extensão e cinco de diâmetro. O grotesco dessa descrição torna pouco convidativo o gesto - até onde podemos saber, aleatório - de decidir se ela correspondia ou correspondeu, em algum momento, à condição física de Vonnegut. Supondo uma resposta afirmativa - mas aí fugimos completamente de nossos propósitos -, talvez a situação tivesse relação com um quadro sifilítico passageiro (o tempo da descrição é o passado: "My penis was..."), tema constante nos romances do autor, inclusive em Breakfast of champions. Em todo caso, nada disso afeta a pragmática, digamos, simbólico-biográfica da autorreferência, não só literária como, num sentido em alguma medida irredutível ao literário, pessoal.
} 


\section{Xeque-escape: a guisa de endgame}

Eis, talvez, a grande e melancólica anedota que Vonnegut não cessa de contar e 'descontar', de afirmar e trair: a de por que não se pode declarar que também o homem, como o Dia do Armistício, ou Romeu e Julieta, ou a música (ou seja, todas essas derivações/abstrações da vida humana), é sagrado. Isso que ele, afinal, não se cansa de declarar, mas que não o impede, por exemplo, de forjar um rito simbólico no qual sugere o estupro do próprio pai. Isso, em todo caso, que só se pode declarar à custa de muitas escusas, volteios e/ou imolações, pois não parece, absolutamente, verdadeiro, a ponto dessa declaração se assemelhar à tolice mais crassa, ou de se precisar submetê-la a algo (uma 'qualidade', um 'fechamento', etc.; em todo caso, uma dificuldade ou propriedade configuradora de uma suposta 'literariedade') implicitamente mais nobre que a própria demanda em jogo, que a estetize e, portanto, justifique.

Mas o belo artístico, em Vonnegut, é sempre autoproclamado, e não no limite, mas na situação - no pôr-em-situação, no pôr-em-estado - da banalidade. Se por defeito ou por virtude é outra questão, mas certamente de forma autoconsciente e no interior de um ágon que extrai dessa decisão - de assumir esse defeito ou explorar essa virtude - efeitos únicos. Quanto ao hermetismo da arte moderna (ou modernista), o mais próximo disso que Vonnegut se permite, ou seja, os entre/interditos de Breakfast, é algo, afinal, muito diferente disso: algo semelhante a dificuldades vexaminosas: não só pelo horror que, ora mal, ora muito mal elas acobertam, como justamente por serem tão explícitas, por demandarem tão claramente um gesto-sentimento que se assombre e incomode com elas, e que por isso mesmo vá além delas. Que produza algo melhor que elas; algo muito íntimo e vivo, e cujo lugar não é o texto, mas o leitor. Íntimo e vivo: que se traduza menos em compreensão - esta, embora sempre falha e incompleta, já foi muito além do que se vive - do que em prática-sentimento. Que só se constitua enquanto "cultura" conquanto comunicação de almas.

$\mathrm{Na}$ ausência da solidariedade, é o vexame que desvela, no jogo de espelhos em que, cedo ou tarde, nossa própria face se reflete, a premência íntima das demandas que não são da arte, mas da vida, ou melhor, que só são da arte enquanto parte da vida, reivindicada em uma supremacia radical face às forças destruidoras mas também à força criadora que se ostenta sob o nome de arte. A arte (ou quase isso) como acinte de si mesma enquanto afirmação irredutível das demandas vivas: nisso, Vonnegut se revela, muito mais que um autor de best-sellers, um sabotador da 'grande arte'. Mesmo nos romances de feição mais realista e, nesse sentido, mais afeitos a uma 'literatura a rigor', como Um pássaro na gaiola e Barba$A z u l$, essa pulsão continua atuante, e certamente seria interesante sondá-la neles. Dificilmente, porém, ela revelaria aí a mesma força que imprime à pequena e estranha obra-prima que é Breakfast of champions.

Recebido em: 07/02/2015. Aprovado em: 19/05/2016. 